\title{
Comparison of Subclavian and Peripheral Intravenous Cannula Insertion in Critically Ill Patients Arriving in Emergency Department
}

\author{
Khalid Azam ${ }^{1}$, Khurram Shahzad ${ }^{2}$, Naima Anwar ${ }^{3}$, Sadiq Zia ${ }^{4}$ \\ 1. Pulmonology, Combined Military Hospital, Lahore, PAK 2. Cardiology, Combined Military Hospital, \\ Lahore, PAK 3. Neurosurgery, Lahore General Hospital, Lahore, PAK 4. Medicine, Zia Hospital, \\ Sadiqabad, PAK
}

$\square$ Corresponding author: Khurram Shahzad, drkhurramshahzad742@gmail.com Disclosures can be found in Additional Information at the end of the article

\section{Abstract}

Introduction: Peripheral intravenous cannulation (PIVC) is a universal procedure to get venous access in hospital emergency settings. Sometimes, for critically ill patients in an emergency department, when we cannot get peripheral venous access, a central venous access could be established by percutaneous subclavian vein cannula insertion through a supraclavicular approach. This study will compare PIVC and percutaneous subclavian vein cannula insertion through supraclavicular approach, and determine which method is more effective and fast in critically ill patients arriving in the emergency department.

Methods: This prospective, randomized clinical trial involved a total of 98 patients arriving in the emergency department in critical condition. Percutaneous subclavian vein cannula insertion through supraclavicular approach was attempted in 49 patients, and PIVC was attempted in other 49 patients. The timing of cannula insertion and the number of attempts for successful cannulation were compared for the two methods.

Results: Percutaneous subclavian vein cannula insertion through supraclavicular approach was successful in 47 out of 49 patients (96\%), and PIVC was successful in 38 out of 49 patients (78\%). Average time of percutaneous subclavian vein cannula insertion through supraclavicular approach was 27.7 seconds (range 15-90 seconds), and the average time of PIVC was 68.64 seconds (range 25-150 seconds).

Conclusion: Compared with PIVC, percutaneous subclavian vein cannula insertion through supraclavicular approach is faster and more effective to gain venous access in critically ill patients arriving in emergency department.

Received 04/25/2018

Review began 06/06/2018 Review ended 08/19/2019 Published 08/21/2019

\section{(C) Copyright 2019}

Azam et al. This is an open access article distributed under the terms of the Creative Commons Attribution License CC-BY 3.0., which permits unrestricted use, distribution, and reproduction in any medium, provided the original author and source are credited.
Categories: Anesthesiology, Cardiac/Thoracic/Vascular Surgery, Emergency Medicine

Keywords: peripheral intravenous cannulation, pivc, subclavian vein cannula insertion, supraclavicular approach

\section{Introduction}

Peripheral intravenous cannulation (PIVC) is a universal procedure to get venous access in hospital emergency settings. Venous access is not only useful for sampling blood required for various laboratory tests, but is also critical for the administration of intravenous medications,

\section{How to cite this article}

Azam K, Shahzad K, Anwar N, et al. (August 21, 2019) Comparison of Subclavian and Peripheral Intravenous Cannula Insertion in Critically III Patients Arriving in Emergency Department. Cureus 11(8): e5452. DOI 10.7759/cureus.5452 
fluids, chemotherapy, parenteral nutrition, and blood products [1].

Sometimes in emergency department, when one can not get peripheral venous access due to some reason like shock, a central venous access could be established effectively and in short time by percutaneous subclavian vein cannula insertion through supraclavicular approach. This central venous access serves all the purposes a peripheral venous access serves, especially the rapid infusion of fluids (via large bore cannulas) needed in emergency settings. This study will compare the subclavian and peripheral IV cannula insertion to determine which method is more effective and faster in critically ill patients arriving in the emergency department.

Moreover this central venous access via cannula can be converted into a central venous line by Seldinger technique that will have additional benefits of increased line security in situ, increased longevity, less infection, larger and multiple lumens for more rapid administration of multiple drugs and fluids at one time, a route for total parenteral nutrition and central venous pressure monitoring.

The infraclavicular approach of subclavian vein catheterization has become an established technique after it was first described by Aubaniac in 1952 [2]. An alternate supraclavicular approach of subclavian vein catheterization was first described by Yoffa in 1965 [3]. However, it is used less often than the old 'conventional' infraclavicular approach. Although there are no randomized trials, the best evidence shows that the supraclavicular approach is more advantageous than the infraclavicular approach of subclavian vein catheterization in a number of aspects.

The incidence of complications like pneumothorax, arterial puncture, hemothorax, brachial plexus, or other nerve injuries, catheter malposition, thrombosis, or thrombophlebitis is zero with percutaneous subclavian vein cannula insertion through the supraclavicular approach.

\section{Materials And Methods}

This prospective, randomized clinical trial involved a total of 98 patients arriving in the emergency department of Combined Military Hospital (CMH), Lahore, Pakistan, in a critical condition from January 2017 to March 2017.

A total of six registrars were trained in both peripheral and subclavian IV cannula insertion through supraclavicular approach $[4,5]$. They were divided into two groups: group A and group $B$, with three members in each group. They were rotated such that one member from each group was present at a time in the emergency department. One was assigned to pass a $3 \mathrm{~cm}$ long $18 \mathrm{G}$ cannula into a peripheral vein, and the other was assigned to pass a similar $3 \mathrm{~cm}$ long $18 \mathrm{G}$ cannula into the subclavian vein through the supraclavicular approach. Both groups had to be assigned both approaches alternatively.

In supraclavicular approach (Garcia et al. technique), the needle prick was done $1 \mathrm{~cm}$ lateral to the lateral head of the sternocleidomastoid muscle and $1 \mathrm{~cm}$ posterior to the clavicle and directed at a 5-degree angle from the coronal plane, 50 degrees from the sagittal plane and 40 degrees from the transverse plane [5].

Timing of cannula insertion was defined as the time from skin-puncture by the needle to the appearance of blood in the hub of the cannula. A third observer observed the timing. Failure was defined as $>3$ attempts or more than three minutes required for the cannula insertion. Success was defined as maintenance of flow by IV infusion for more than one hour.

The subclavian cannula was later on stitched, and all of them were later on converted into 


\section{Cureus}

central venous lines by the Seldinger technique from 1-8 hours after cannula insertion.

The Chi-Square test was used to assess the relationship between subclavian and peripheral IV cannulation success rate. P-values less than 0.05 indicated statistical significance. All statistical calculations were performed using SPSS version 20 software.

\section{Results}

The study included a total of 98 patients, with percutaneous subclavian vein cannula insertion through a supraclavicular approach attempted in 49 patients and peripheral IV cannula insertion attempted in the other 49 patients. Percutaneous subclavian vein cannula insertion through supraclavicular approach was successful in 47 patients (96\%) (Figure 1), and peripheral IV cannula insertion was successful in 38 patients (78\%) (Figure 2).

\section{Subclavian}

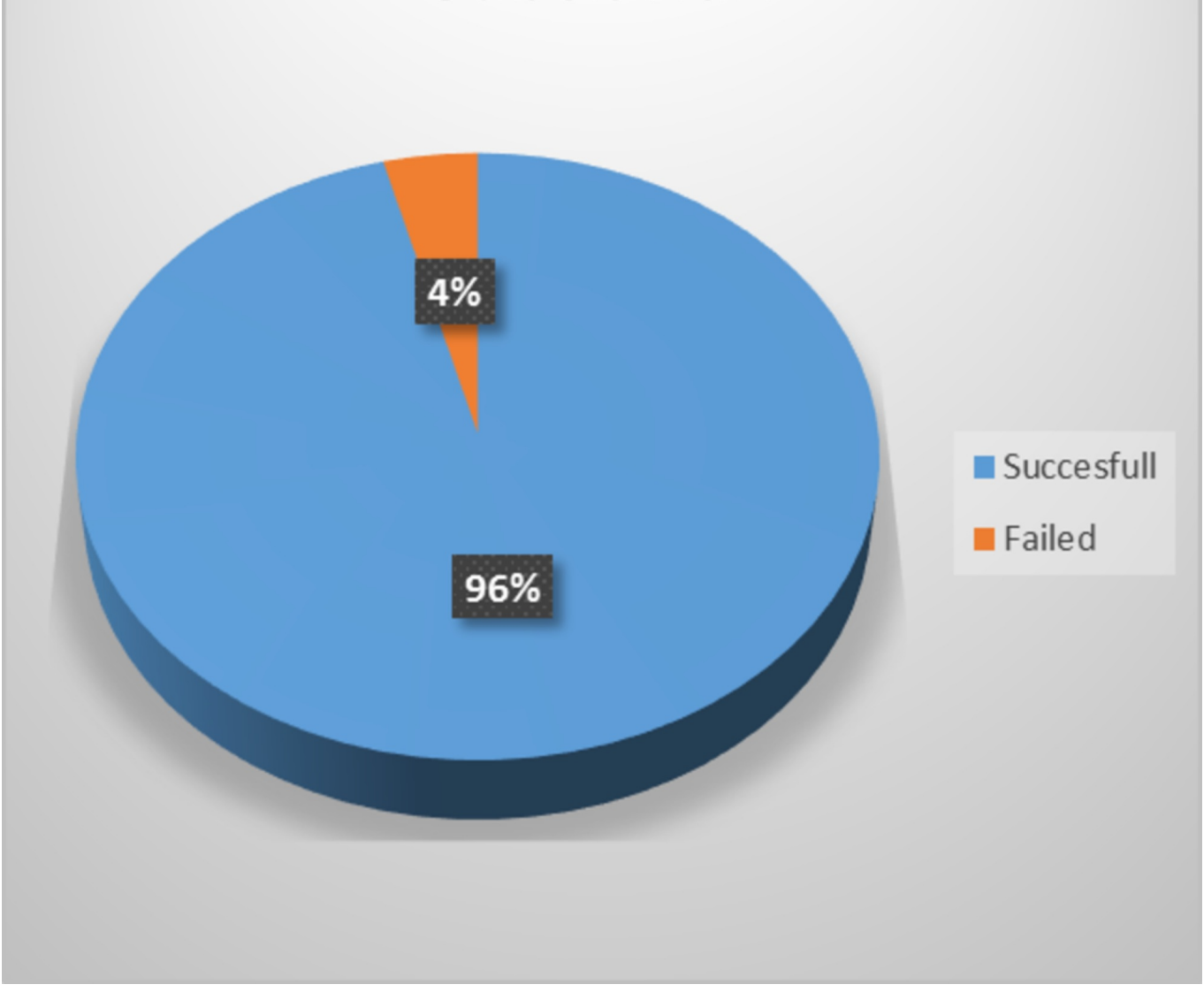

FIGURE 1: Percentage success of percutaneous subclavian vein cannula insertion through supraclavicular approach 


\section{Cureus}

\section{Peripheral}

\section{$22 \%$}

\section{FIGURE 2: Percentage success of peripheral IV cannula}

insertion

Average time of percutaneous subclavian vein cannula insertion through supraclavicular approach was 27.7 seconds (range: $15-90$ seconds) and average time of peripheral IV cannula insertion was 68.64 seconds (range: $25-150$ seconds) (Figure 3). 


\section{Cureus}

\section{Average Time in Seconds}

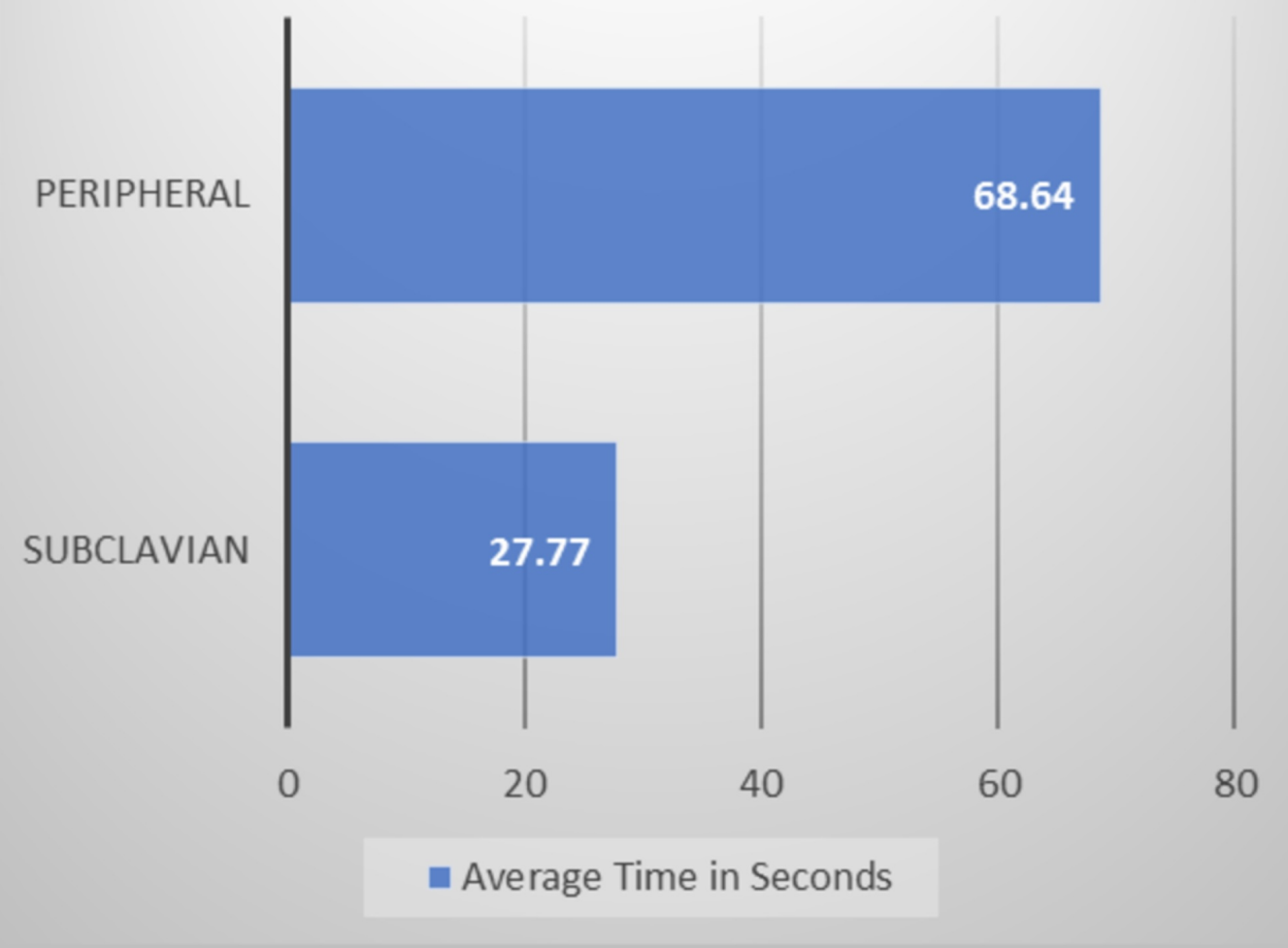

\section{FIGURE 3: Average time of percutaneous subclavian vein cannula insertion through supraclavicular approach versus average time of peripheral IV cannula insertion}

The average number of attempts in successful percutaneous subclavian vein cannula insertion through the supraclavicular approach was 1.36, and in successful peripheral IV cannula insertion was 1.86. Percutaneous subclavian vein cannula insertion through the supraclavicular approach was successful in 33 patients (67\%) in the first attempt, and 11 patients (22\%) in the second attempt. Peripheral IV cannula insertion was successful in 13 patients $(27 \%)$ in the first attempt, 19 patients (39\%) in the second attempt.

Prior to running analyses, the assumption of normality was assessed by visualizing the data through histograms. It was also supplemented with statistical tests such as KolmogorovSmirnov and Shapiro-Wilk test.

Mann Whitney U test was run to analyze the difference in time taken (mean rank) by percutaneous subclavian vein cannula insertion and PIVC in critically ill patients. The difference in the number of attempts for a successful cannulation (mean rank) by the two methods was also assessed with this test.

Independent sample Mann Whitney U test revealed that successful percutaneous subclavian vein cannula insertion through supraclavicular approach required less number of attempts than successful PIVC (standardized test statistic $=3.182, \mathrm{P}<.001, \mathrm{n}=83$ ). Detailed results have been presented in Figure 4. 


\section{Cureus}

\section{Independent-Samples Mann-Whitney U Test}

Approach

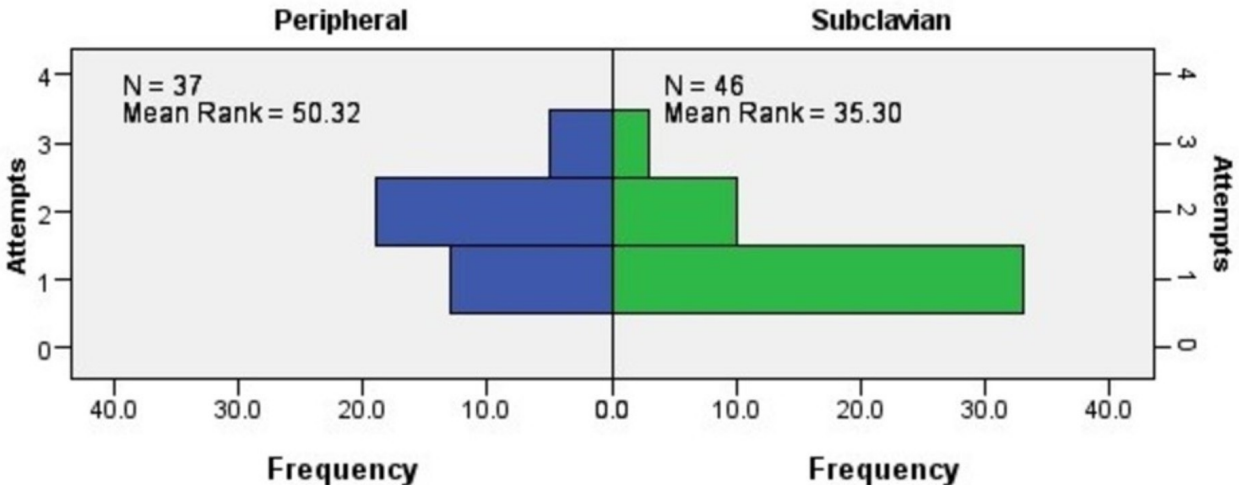

\section{FIGURE 4: Difference in number of attempts for a successful} cannulation by the two methods

Independent sample Mann Whitney U test revealed that percutaneous subclavian vein cannula insertion through supraclavicular approach required less time than PIVC for a successful cannulation (statistic $=6.391, \mathrm{P}<.001, \mathrm{n}=83$ ). Detailed results have been presented in Figure 5 .

\section{Approach}

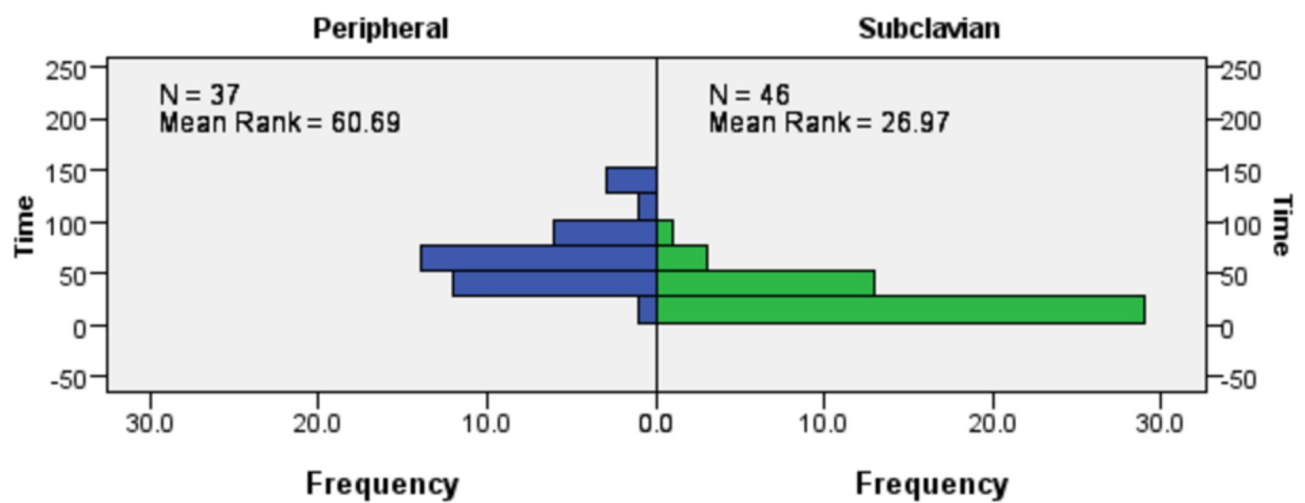

FIGURE 5: Difference in time taken by percutaneous subclavian vein cannula insertion and PIVC

\section{Discussion}

PIVC is the most common procedure to get venous access in hospitals, and its omnipresence was shown in a point prevalence study done in a European hospital; over $84 \%$ of patients had a vascular access device of some type, with $80 \%$ of these PIVCs [6].

Occasionally PIVC fails, and the failure rate is greater in critically ill patients arriving in emergency departments. Risk factors for PIVC failure have been found out in large prospective studies, and prevention of PIVC insertion failure is increasing with the use of specialist teams [7-9]. 
Successful PIVC is more likely if performed by clinicians who are more experienced in this procedure and have an increased perception of the success probability. Some patient factors also increase the chances of successful cannulation, e.g., 'normal' body weight, visible vein/s, and cubital fossa placement [10].

When PIVC fails, usually central venous access is achieved via catheterization. Moayedi et al. successfully inserted a catheter into the internal jugular vein in patients with difficult intravenous access in $88 \%$ of cases, with a mean time of $4.4 \mathrm{~min}$. The only complication was the loss of patency that occurred in $14 \%$ of cases [11]. In our study, we got central venous access into the subclavian vein through a supraclavicular approach with a $3 \mathrm{~cm}$ long $18 \mathrm{G}$ cannula successfully in $96 \%$ of cases with a mean time of 27.7 seconds.

There are many anatomic advantages of the subclavian vein for the venous access that include its large diameter, absence of valves, and ability to remain patent and in a relatively constant position [3,12]. Subclavian vein catheterization has a lower risk of thrombosis and catheterrelated infection than femoral or internal jugular vein catheterization [13]. In our study, the incidence of complications like pneumothorax, arterial puncture, hemothorax, brachial plexus or other nerve injuries, catheter malposition, thrombosis or thrombophlebitis is zero with percutaneous subclavian vein cannula insertion through the supraclavicular approach.

Although ultrasound is a huge progress in the placement of central lines, it is not always available in most of the hospital settings. For the same reason, landmark-based central line placement remains the most prevalent technique. The supraclavicular approach of subclavian vein catheterization is at least as safe as other approaches. Moreover, it is easy to perform, and there are fewer chances of misplacement [14].

Supraclavicular approach of subclavian vein catheterization is superior to infraclavicular approach in a number of aspects: a shorter distance from skin to vein; a larger target area; a well-defined insertion landmark (the clavisternomastoid angle); a straighter path to the superior vena cava; less proximity to the lung; and lesser chances of pleural or arterial puncture [3,12,15-18]. Moreover, the supraclavicular approach less often results in interruption of cardiopulmonary resuscitation (CPR) or tube thoracostomy than the infraclavicular approach $[19,20]$.

Sterner et al. carried out a comparison of the supraclavicular approach and the infraclavicular approach for subclavian vein catheterization [21]. There were 38 failures (15.5\%) among 245 patients in the supraclavicular group, with one malposition and five complications. There were 51 failures (20.0\%) among 255 patients in the infraclavicular group, with 21 malpositions and 13 complications. No differences were significant except that of malpositions (P less than .01). Analysis of this comparison study reveals that both the infraclavicular and supraclavicular approaches to subclavian vein catheterization are good choices, with little difference in success rate or complications. Using the other approach, if the initial approach was unsuccessful, resulted in a high overall success rate and a low overall complication rate.

A randomized prospective study by Dronen et al. compared the supraclavicular and infraclavicular approaches in 76 patients undergoing CPR [19]. Forty-four supraclavicular attempts and 45 infraclavicular attempts were analyzed. Successful cannulation rates with the two approaches were comparable (90\% with the supraclavicular approach and $84 \%$ with the infraclavicular approach, $\mathrm{p}>0.05$ ). The mean number of needle sticks required for the cannulation was similar with the two approaches. However, the incidence of catheter malpositioning or kinking was significantly greater with the infraclavicular approach (26\% versus $7 \%$ with the supraclavicular approach, $\mathrm{p}<0.05$ ). Moreover, undue CPR interruption (for 》 5 seconds) occurred in $20 \%$ of supraclavicular attempts and $40 \%$ of infraclavicular attempts 
$(\mathrm{p}<0.025)$. No major complications were noted with both approaches. Based on this study, the subclavian vein catheterization via the supraclavicular approach is reasonably superior to the infraclavicular approach when central venous access is required during CPR.

Patrick et al. showed the success of the supraclavicular approach using Yoffa's original technique (success rate, $97.7 \%$ ) as well as modifications to patient position, landmarks, and angles (success rate, $98.6 \%$ ).

\section{Conclusions}

Compared with peripheral IV cannula insertion, percutaneous subclavian vein cannula insertion through the supraclavicular approach is faster and more effective in gaining venous access in critically ill patients arriving in the emergency department.

\section{Additional Information \\ Disclosures}

Human subjects: Consent was obtained by all participants in this study. Research Review Board Combined Military Hospital Lahore issued approval 78/2018. The Research Review Board Combined Military Hospital Lahore has no objection on carrying out of study on research article titled "Comparison of Subclavian and Peripheral Intravenous Cannula Insertion in Critically Ill Patients Arriving in Emergency Department". Animal subjects: All authors have confirmed that this study did not involve animal subjects or tissue. Conflicts of interest: In compliance with the ICMJE uniform disclosure form, all authors declare the following:

Payment/services info: All authors have declared that no financial support was received from any organization for the submitted work. Financial relationships: All authors have declared that they have no financial relationships at present or within the previous three years with any organizations that might have an interest in the submitted work. Other relationships: All authors have declared that there are no other relationships or activities that could appear to have influenced the submitted work.

\section{Acknowledgements}

We would like to acknowledge Ahmad Waqas with help in the statistical analysis of data, Ahmad Marjan with help in the paper writing process and Waqas Ahmad with the help in publishing process.

\section{References}

1. Shaw SJ: How to insert a peripheral cannula . Nurs Stand. 2016, 31:42-47. 10.7748/ns.2016.e10570

2. Aubaniac R: A new route for venous injection or puncture: the subclavicular route, subclavian vein, brachiocephalic trunk. Sem Hop. 1952, 28:3445-7.

3. Yoffa D: Supraclavicular subclavian venepuncture and catheterization. Lancet. 1965, 2:614-7.

4. Ortega R, Sekhar P, Song M, Hansen CJ, Peterson L: Peripheral intravenous cannulation. N Engl J Med. 2008, 359:e26. 10.1056/NEJMvcm0706789

5. Garcia JM, Mispireta LA, Pinho RV.: Percutaneous supraclavicular superior vena caval cannulation. Surg Gynecol Obstet. 1972, 134:839-41.

6. Fernandez-Ruiz M, Carretero A, Diaz D, et al.: Hospital-wide survey of the adequacy in the number of vascular catheters and catheter lumens. J Hosp Med. 2014, 9:35-41. 10.1002/jhm.2130

7. Wallis MC, McGrail M, Webster J, et al.: Risk factors for peripheral intravenous catheter failure: a multivariate analysis of data from a randomized controlled trial. Infect Control Hosp Epidemiol. 2014, 35:63-8. 10.1086/674398

8. Lee WL, Chen HL, Tsai TY, et al.: Risk factors for peripheral intravenous catheter infection in 
hospitalized patients: a prospective study of 3165 patients. Am J Infect Control. 2009, 37:6836. 10.1016/j.ajic.2009.02.009

9. Carr PJ, Higgins NS, Cooke ML, Mihala G, Rickard CM: Vascular access specialist teams for device insertion and prevention of failure. Cochrane Database of Syst Rev. 2014, CD011429. 10.1002/14651858.CD011429

10. Carr PJ, Rippey JC, Budgeon CA, et al.: Insertion of peripheral intravenous cannulae in the emergency department: factors associated with first-time insertion success. J Vasc Access. 2016, 17:182-90. 10.5301/jva.5000487

11. Moayedi S, Witting M, Pirotte M.: Safety and efficacy of the "Easy Internal Jugular (IJ)": an approach to difficult intravenous access. J Emerg Med. 2016, 51:636-642. 10.1016/j.jemermed.2016.07.001

12. Defalque R.: Subclavian venipuncture: a review. Anesth Analg. 1968, 47:677-82.

13. McGee DC, Gould MK: Preventing complications of central venous catheterization . N Engl J Med. 2003, 348:1123-33. 10.1056/NEJMra011883

14. Tomar GS, Chawla S, Ganguly S, Cherian G, Tiwari A: Supraclavicular approach of central venous catheter insertion in critical patients in emergency settings: Re-visited. Indian J Crit Care Med. 2013, 17:10-5. 10.4103/0972-5229.112145

15. Brahos GJ: Central venous catheterization via the supraclavicular approach. J Trauma. 1977, 17:872-7.

16. Brahos GJ, Cohen M: Supraclavicular central venous catheterization: technique and experience in 250 cases. Wisconsin Med J. 1981, 80:36-8.

17. Muhm M, Sunder-Plassmann G, Apsner R, Kritzinger M, Hiesmayr M, Druml W: Supraclavicular approach to the subclavian/innominate vein for large-bore central venous catheters. Am J Kidney Dis. 1997, 30:802-8. 10.1016/S0272-6386(97)90085-8

18. Apsner R, Schulenburg A, Sunder-Plassmann G, et al.: Routine fluoroscopic guidance is not required for placement of Hickman catheters via the supraclavicular route. Bone Marrow Transplant. 1998, 21:1149-52. 10.1038/sj.bmt.1701250

19. Dronen S, Thompson B, Nowak R, Tomlanovich M: Subclavian vein catheterization during cardiopulmonary resuscitation: a prospective comparison of the supraclavicular and infraclavicular percutaneous approaches. JAMA. 1982, 247:3227-30.

20. Gorchynski J, Everett WW, Pentheroudakis E: A modified approach to supraclavicular subclavian vein catheter placement: the pocket approach. Calif J Emerg Med. 2004, 5:50-4.

21. Sterner S, Plummer DW, Clinton J, Ruiz E: A comparison of the supraclavicular approach and the infraclavicular approach for subclavian vein catheterization. Ann Emerg Med. 1986, 15:421-4.

22. Patrick SP, Tijunelis MA, Johnson S, Herbert ME: Supraclavicular subclavian vein catheterization: the forgotten central line. West J Emerg Med. 2009, 10:110-114. 